\title{
Método UEP aplicado à pequena empresa fabril: uma relação custo/benefício favorável
}

\begin{abstract}
Marluce Lembeck
MBA em Gestão Empresarial pela Fundação Getúlio Vargas - FGV Professora da Universidade do Sul de Santa Catarina - UNISUL Av. José Acácio Moreira, 787. Dehon. Tubarão/SC. CEP: 88.704-

900

E-mail: Marluce.lembeck@unisul.br

Rodney Wernke Doutorado em Engenharia de Produção pela Universidade Federal de Santa Catarina UFSC Professor da Universidade do Sul de Santa Catarina - UNISUL Av. José Acácio Moreira, 787. Dehon. Tubarão/SC. CEP: 88.704-

900

E-mail: rodney.wernke@gmail.com
\end{abstract}

\section{RESUMO}

Este estudo tem por objetivo avaliar a possibilidade de mensurar os custos de transformação do mix comercializado por uma pequena fábrica de confecções underwear, utilizando o método UEP de modo economicamente viável quanto à implantação e operacionalização nesse porte de empresa. Para tanto, foi empregada metodologia do tipo descritiva no formato de estudo de caso, com abordagem qualitativa. Inicialmente, foi efetuada uma revisão da literatura a respeito desse método de custeio, em que foram abordados aspectos como histórico, conceitos, princípios norteadores, etapas a serem percorridas para implementá-lo, benefícios informativos e limitações associadas. Em seguida, foram apresentadas as principais características do estudo de caso realizado com descrição da empresa enfocada e das fases seguidas para aplicar o método UEP. Posteriormente, foram elencadas as informações gerenciais proporcionadas e ressaltadas as limitações associáveis à metodologia utilizada. Concluiu-se pela aplicabilidade do método no contexto de fábricas de pequeno porte. Além disso, restou a conclusão de que não é necessário despender recursos expressivos para implementar e operacionalizar uma planilha de custos adaptada ao âmbito de pequenas indústrias semelhantes, o que contradiz parte da literatura que trata de métodos de custeio.

Palavras-chave: UEP. Estudo de caso. Viabilidade em pequena empresa.

UEP method applied for small production company: a favorable relation cost/benefit 


\section{ABSTRACT}

This study aimed to evaluate the possibility of measuring the transformation costs of the mix sold by a small underwear factory using the UEP method in an economically viable manner regarding the implementation and operation in this company size. For that, a descriptive methodology was used, in the case study format, with a qualitative approach. Initially, a review of the literature on this costing method was performed, which covered aspects such as history, concepts, guiding principles, steps to be taken to implement it, informational benefits and associated limitations. Following are presented the main features of the case study conducted with description of the focused company and the steps followed to apply the UEP method. Subsequently, the management information provided was listed and the limitations associated with the methodology used were highlighted. It was concluded by the applicability of the method in the context of small factories. Moreover, the conclusion remains that there is no need to spend significant resources to implement and operationalize a cost spreadsheet adapted to the scope of similar small industries, which contradicts part of the literature dealing with costing methods.

Keywords: UEP. Case study. Viability in small company.

\section{INTRODUÇÃO}

Uma informação contábil útil para os gestores de pequenas fábricas é o valor (em $\mathrm{R} \$$ ) do custo de transformação por unidade produzida, pois facilita a tomada de decisões por parte do administrador acerca de iniciativas para otimizar os resultados, especialmente no tocante à lucratividade de produtos. Nesse sentido, a mensuração desse custo e das várias atividades relacionadas à fabricação requer a utilização de um conjunto de procedimentos específicos (Kuhn, Francisco, \& Kovaleski, 2011).

Porém, em determinadas empresas industriais os processos relacionados aos itens comercializados podem ser complexos e abranger diversas etapas de produção, que exigem a utilização de funcionários e equipamentos com maior ou menor intensidade, conforme o tipo de produto ou linha de produção. No citado contexto, os gerentes se deparam com a necessidade de alocar custos com folha de pagamento, depreciação (fabril e predial), energia elétrica, aluguel de equipamentos ou das instalações e outros insumos aos diferentes itens produzidos ou às diversas atividades 
executadas, visto ser fundamental a apropriação desses custos quando se trata da gestão da rentabilidade de produtos ou segmentos (Guerreiro, 2011).

Ao se depararem com esse problema, as indústrias de pequeno porte tendem a empregar metodologias simplificadas (como dividir o custo total pela quantidade produzida) que acarretam valores inconsistentes de custo fabril unitário, principalmente se houver uma variedade grande de modelos, pesos e formatos na produção do período. Com essa divisão, o custo unitário de transformação (exclusive a matériaprima consumida) ficaria igual em todos os produtos, independentemente de ser um item de tamanho pequeno, médio ou grande, por exemplo (Wernke, Junges, Lembeck, \& Zanin, 2015).

Como forma de minimizar os entraves à determinação dos custos dos produtos, podem ser adotados métodos de custeio que, segundo Bornia (2009), referem-se às formas como os dados do processo operacional são tratados para obter as informações de custos. Para Luiz, Gasparetto, Lunkes e Schnorrenberger (2014), a seleção do método de custeio mais adequado depende das características da organização, do ramo de atividade, das peculiaridades dos produtos ou serviços, da disponibilidade de recursos para manutenção do método, dos objetivos em relação às informações pretendidas, entre outros aspectos.

Entre as possibilidades para resolver problemas de custeamento está a utilização do método UEP, cuja concepção básica é a de unificar a medição da produção industrial por meio de uma única unidade de medida abstrata (Cambruzzi, Balen, \& Morozini, 2009). Para Souza (2014), a implementação deste método proporciona uma análise detalhada do processo de produção e o aumento da acurácia das informações de custos. Mas a base teórica do UEP pode ser de difícil entendimento para leigos, o que tende a prejudicar a aceitação de iniciativas a respeito se os benefícios relacionados não forem evidenciados corretamente.

Esse aspecto é agravado com as menções na literatura acerca das dificuldades para implementar e operacionalizar métodos de custeio mais complexos no âmbito de pequenas empresas industriais, especialmente quanto aos dispêndios requeridos com 
pessoal, equipamentos, softwares específicos, coleta e processamento de dados etc. (Pereira, 2015; Souza, 2014; Fontoura, 2013; Martins \& Rocha, 2010; Souza \& Diehl, 2009; Kaplan \& Anderson, 2004). A partir do exposto, é pertinente cogitar se o método UEP pode ser considerado uma alternativa de custeamento para pequenas empresas industriais porque, a priori, parece ter uma configuração mais apropriada para organizações de grande porte.

Surge, então, a questão de pesquisa que se pretende responder: o método de custeio UEP pode ser uma opção viável para empresas industriais de pequeno porte, sem despender montante elevado de recursos para implementar e operacionalizar essa forma de custeio? Nesse sentido, o objetivo da pesquisa foi avaliar a possibilidade de mensurar os custos de transformação do mix comercializado por uma pequena fábrica de confecções underwear utilizando o método UEP de modo economicamente viável quanto à implantação e operacionalização nesse porte de empresa.

Convém salientar que estudos como este se justificam por dois aspectos. $\mathrm{O}$ primeiro relaciona-se ao mencionado em parágrafo anterior acerca do montante de recursos a ser despendido para possibilitar o uso dos métodos de custeio mais sofisticados do ponto de vista da literatura (ABC, TDABC, UEP etc.), que poderia desestimular a busca por aprimoramentos a respeito nas empresas de menor porte.

Entretanto, com determinadas adequações (como o uso de planilha eletrônica em vez de software, de estimativas em detrimento de equipe para coleta periódica de dados etc.) talvez possa ser evidenciado que a dificuldade apontada na literatura seja contornável no âmbito da realidade de empresas de menor porte, como se pretende demonstrar nesta pesquisa. Essa ênfase está alinhada com Baldvinsdottir, Mitchell e Norreklit (2010) e Lukka (2010), que entendem haver necessidade de mais estudos acadêmicos que contribuam para que as empresas possam implementar determinados artefatos na prática gerencial.

O segundo aspecto está relacionado ao reduzido número de artigos publicados em revistas acadêmicas brasileiras sobre o método UEP, notadamente nos periódicos da seara contábil. Acerca disso, Pereira (2015) cita que boa parte da literatura 
acadêmica nacional da área de Contabilidade não dedica, ainda, muito espaço a este método, apesar do UEP já ser utilizado, na prática, por mais de uma centena de empresas brasileiras (Allora \& Oliveira, 2010).

Nesse sentido, Oyadomari, Cardoso, Mendonça, Antunes e Aguiar (2013) defendem que a contabilidade gerencial deve ser estudada pela academia também pela perspectiva dos práticos, sendo que esses estudos podem ser "à luz de uma organização específica, e não necessariamente sobre o estado da arte, uma vez que as organizações podem se encontrar em diferentes estágios de adoção dessas práticas" de controle gerencial.

\section{REVISÃO DA LITERATURA}

Nesta pesquisa, não se tem a pretensão de comparar métodos de custeio ou definir qual seria o melhor para determinado segmento empresarial. Por isso, entre as opções disponíveis na literatura (ABC, TDABC, UEP, Absorção, Variável etc.) foi priorizado o Método UEP em virtude de que este é adequado ao contexto de fabricantes de produtos seriados (Wernke, 2005; Bornia, 2009; Souza \& Diehl, 2009; Zonatto, Silva, Toledo, \& Drebes, 2012; Wernke, Lembeck, Junges, \& Ritta, 2013), como é o caso da empresa onde foi realizada esta pesquisa.

Referido método surgiu da ideia de unificar a medição da produção fabril, por meio de uma só unidade de medida abstrata, conforme Allora (1988) e Allora e Allora (1995). Contudo, Pereira (2015) registra que, desde a década de 1940, já existiam métodos que visavam atingir o mesmo objetivo e citou alguns exemplos a respeito. Mais adiante, a partir do aprimoramento da concepção original da Unidade GP, foi desenvolvido na França, em 1977, o método UP (Unité de Production), que foi rebatizado em 1995 com a nomenclatura de Unité de Valeur Ajouteé (UVA), que vem sendo divulgado pelos consultores Jean Fievez e Robert Zaya (Levant \& De La Villarmois, 2004; Ferrari, 2012; Luiz et al., 2014; Souza, 2014). 
Slavov (2013) cita que o UEP foca o custo de transformação de operações homogêneas executadas em postos operativos, geralmente em fábricas com mix de produção diversificado. No mesmo sentido, Gantzel e Allora (1996) enfatizam que o referido método possibilita, por meio de uma única unidade de medida, mensurar toda $\mathrm{e}$ qualquer produção, por mais diversificada que seja. Souza (2011) afirma que o UEP é um "método de custeio que estabelece quais elementos de custo serão considerados na apuração do custo dos objetos de custeio". Apesar de normalmente serem referidos como produtos e/ou serviços e, dependendo do tipo de informação que se deseja obter, tais objetos podem ser os mais variados possíveis (linhas de produtos/serviços, departamentos, centros de custos, clientes, canal de distribuição etc.). A principal diferença entre os métodos de custeio está nos tipos de custos considerados na mensuração: custos variáveis (na sua grande maioria custos diretos) e custos fixos (na sua grande maioria custos indiretos).

Wernke e Lembeck (2012) aduzem que, no UEP, os custos unitários dos produtos são resumidos em custos das matérias-primas consumidas e custos de transformação. Quanto às matérias-primas consumidas, o custeio de cada produto é obtido facilmente nas fichas técnicas individuais dos mesmos. Assim, o método UEP preocupa-se basicamente com os custos de transformação, que representam o esforço realizado pela empresa para conversão da matéria-prima em produto pronto para ser comercializado.

Para implantação desse método de custeio, Souza e Diehl (2009) mencionam que é necessário: (i) dividir a fábrica em postos operativos (POs); (ii) calcular os potenciais de produção dos POs; (iii) definir um produto-base; (iv) calcular o foto-custo do produto-base; ( $v$ ); calcular o potencial produtivo dos postos operativos; e ( vi) cálculo do valor dos produtos em UEPs.

\subsection{Vantagens associadas ao Método UEP}

No tocante às vantagens proporcionadas pelo método UEP, Allora (1988) assevera que o benefício maior reside na homogeneidade que esse método propicia, 
ou seja, "quaisquer que sejam os objetos fabricados e seus processos de fabricação, a produção dos mesmos precisa de uma parte desse elemento único que é o esforço de produção desenvolvido pela usina". Gantzel e Allora (1996) relatam que esse método unifica os controles de gestão produtiva das empresas e, por meio de uma única unidade de medida, permite mensurar toda e qualquer produção, por mais diversificada que seja. Aduzem, ainda, que o Método UEP é indicado para situações em que há grande variedade de bens e serviços produzidos por uma empresa na qual haja dificuldade em estabelecer uma medida específica para os produtos.

Para Schultz, Silva e Borgert (2008), como "esse método faz com que os custos de produção sejam absorvidos pelos produtos, também é possível a utilização das informações provenientes de um sistema nele baseado para fins de atendimento da contabilidade financeira, de acordo com as normas que a regem".

Bornia (2009) registra que o método UEP possibilita o "acompanhamento da produção com o uso de medidas físicas. Três indicadores que podem ser utilizados para essa finalidade são: eficiência, eficácia e produtividade horária". Comenta, ainda, que o parâmetro "eficiência" representa o nível de produção alcançado (em UEPs), comparado com a produção (em UEPs) que seria normalmente conseguida no período de expediente. Já o índice de "eficácia" relaciona a produção obtida com a produção que teoricamente se deveria obter no período efetivamente trabalhado. No que tange à "produtividade horária", esta seria determinada pela divisão da produção de UEPs do período pelo tempo de trabalho. Referido autor defende que esses parâmetros podem ser determinados para um posto operativo, para um setor ou para toda a fábrica, propiciando uma boa forma de acompanhamento do desempenho industrial.

Souza e Diehl (2009) citam que esse método pode ser aplicado para: cálculo dos custos de transformação; cálculo da lucratividade dos produtos; definição do preço dos produtos; orientação da programação de produção; mensuração da produção; apoio à análise de valor; definição das capacidades de produção; comparação de processos; elaboração de medidas de desempenho; análise da viabilidade de aquisição 
de novos equipamentos; definição de máquinas e pessoal; análise da eficácia das horas-extras; definição de prêmios de produtividade e programação da produção.

\subsection{Desvantagens atribuíveis ao Método UEP}

Apesar dos benefícios informativos que propicia, o UEP apresenta algumas limitações. Bornia (2009) salienta que, como esse método enfoca apenas a transformação dos produtos, as despesas de estrutura não são abrangidas pelo mesmo. Comenta, ainda, que o descaso para com essas despesas é um problema do método, pois tais gastos vêm aumentando ao longo dos anos e merecem uma análise detalhada para sua racionalização no processo de combate às perdas e ao trabalho adicional.

Na mesma direção, Martins e Rocha (2010) registram que esse método "trata, fundamentalmente, dos custos de transformação, como no Custeio por Absorção Parcial, mas sem contemplar o custo de overhead, como logística de suprimento e de produção, controle de qualidade etc."

Meyssonnier (2003) critica o conceito de constantes ocultas, pertinente aos métodos que utilizam o cálculo de equivalência (como o UVA e o UEP), já que se caracterizam por partir do pressuposto de que a relação dos postos operativos se mantêm constantes ao longo do tempo, mesmo em face de alterações tecnológicas ou econômicas. Assim, esses métodos teriam o problema de não considerar a possibilidade de melhoria contínua dos processos, o que leva à conclusão de que os métodos de apuração de custos baseados em produção equivalente estariam longe da simplicidade e da robustez atribuídas pelos defensores dessas formas de custeamento.

Por sua vez, Gervais (2006) concluiu que realizar atualizações constantes nesses métodos que usam equivalência é necessário para minimizar erros relacionados com ganhos de produtividade motivados por alterações decorrentes do aprendizado dos operadores de máquinas, de erros de medição de tempos etc. É válido citar que esta é uma limitação que pode também ser atribuída ao TDABC, que se fundamenta na mesma variável "tempo". 
Outro aspecto problemático apontado por Levant e Zimnowitch (2013), De La Villarmois e Levant (2011), Meyssonnier (2003), Gervais e Levant (2007) e Gervais (2009) é que não se conseguiu eliminar as incertezas técnicas nos modelos de equivalência, como é o caso da escolha do produto de referência (ou produto-base na terminologia adotada no âmbito do método UEP). Nesse rumo, Malaquias, Giachero, Costa e Lemes (2007) também ressaltam que no método UEP a subjetividade está presente na determinação do produto-base. Como a escolha do produto-base pode recair sobre o produto que passa por um número maior de postos operativos ou por um produto que passe pelos postos mais importantes, tal possibilidade não apresenta objetivismo algum neste critério de escolha.

Pereira (2015) elenca como limitações do UEP os seguintes aspectos: não identifica a parcela de custos associados a perdas do processo; necessita revisão constante dos cálculos e da estrutura de produção; desconsidera as despesas de estrutura; tende a ser aplicável apenas ao ambiente industrial; não permite gerenciar os gastos não fabris; apresenta dificuldades de aplicação em empresas onde os produtos variam regularmente; tem elevada complexidade e custo de implementação; necessita de operações relativamente padronizadas; apresenta subjetividade na escolha do produto-base e não abrange gastos de overhead (como logística de suprimento, controle de qualidade etc.).

\section{METODOLOGIA}

De forma resumida, é possível caracterizar este estudo pelos ângulos da natureza, objetivos, abordagem e procedimentos. Quanto à natureza, esta pesquisa é aplicada ou empírica, de vez que objetiva gerar conhecimentos para a aplicação prática e dirigidos à solução de problemas específicos (Silva \& Menezes, 2005). Em termos de seus objetivos, é descritiva, visto que envolve descrição, registro, análise e interpretação do fenômeno, sendo que, em sua maioria, se utiliza da comparação e contraste (Salomon, 1999). No que tange aos procedimentos adotados, é um estudo de 
caso, pois concentra-se em uma única empresa, e suas conclusões limitam-se ao contexto desse objeto de estudo (Yin, 2005). Sobre a forma de abordagem do problema, é qualitativa, pois concebem-se análises mais profundas em relação ao fenômeno que está sendo estudado, visando destacar características que não são passíveis de observar por meio de um estudo quantitativo, conforme Raupp e Beuren (2010).

A pesquisa foi realizada tendo por base os dados do mês de outubro de 2018, de uma pequena indústria de confecções sediada no município de Pedras Grandes (SC). A opção por esse período deveu-se à facilidade de acesso aos dados e porque a produção da empresa é relativamente estável em termos de volumes físicos processados ao longo dos meses.

Referida empresa contava com 23 colaboradores por ocasião da pesquisa: três trabalhavam na parte administrativa e os demais na produção. Quanto à escolha da empresa, esta ocorreu por dois motivos. A primeira razão está ligada à possibilidade de acesso aos dados necessários por parte dos pesquisadores, facultada pelo proprietário do empreendimento, o que restringe os resultados a esse contexto empresarial. A segunda razão para priorizar essa entidade é que esta possui estrutura produtiva complexa, com 42 postos operativos, e trabalhava com mix composto por mais de uma centena de produtos. Essa configuração acarreta maior dificuldade para coleta de dados e elaboração dos cálculos necessários para apurar o custo de transformação de forma tecnicamente consistente.

Nesse sentido, pela dificuldade de competir com empresas maiores, o proprietário afirmava que tinha necessidade de informações mais confiáveis a respeito do custo de fabricação dos diversos produtos que comercializava. Segundo relatou aos pesquisadores, calculava o custo unitário de transformação dos itens vendidos dividindo o gasto mensal (com salários, encargos, energia elétrica e manutenção, sem computar a depreciação do maquinário e do prédio) pela quantidade média de produção. Mesmo sabendo que isso levava a valores de custos com distorções significativas, o gestor utilizava esse procedimento tendo em vista desconhecer outras formas de cálculo. Por 
isso, permitiu o acesso aos dados e informações necessários para a realização deste estudo que fundamentou trabalho de conclusão de curso de graduação orientado por um dos autores.

Por se tratar de um estudo de caso, no que concerne à coleta de dados, Marques, Camacho e Alcantara (2015) afirmam que nesse tipo de pesquisa é possível combinar entrevistas, pesquisas em arquivos, questionário, relatórios verbais e observações, sendo que as evidências podem ser qualitativas e quantitativas. $\mathrm{Na}$ mesma direção, Yin (2005) recomendou diversas fontes para coligir dados nesse tipo de estudo: documentos e registros; entrevistas; observação direta e participante; evidências físicas etc. No caso desta pesquisa, os procedimentos de coleta de dados foram realizados entre novembro e dezembro de 2018, abrangendo o contexto de outubro de 2018.

Para tanto, foram empregadas as técnicas de conversas informais (entrevistas não estruturadas) com o gestor da entidade, líderes de produção e com o contador, bem como foi efetuada uma análise documental (nos controles internos e na contabilidade terceirizada) com a intenção de conhecer a situação vigente no que tange aos dados necessários para efetuar o estudo pretendido. Na sequência, iniciou-se a coleta dos dados requeridos para execução do trabalho nos controles internos existentes, além de outros informes mais específicos que foram obtidos junto ao gerente e ao contador da firma. Esses procedimentos permitiram obter dados documentados e também informações que não estavam registradas em relatórios ou controles internos, mas que ajudam a explicar a rotina produtiva da empresa estudada.

Por outro lado, no que tange aos aspectos formais, no sentido de manter o rigor da pesquisa e atender aos requisitos de triangulação de dados propostos por Yin (2005), a coleta de dados deu-se pela utilização de entrevistas semiestruturadas, pesquisa documental e observação. Também para atestar o rigor metodológico deste estudo de caso, foram utilizados os parâmetros recomendados por Marques, Camacho e Alcântara (2015) quanto ao objeto de estudo, à coleta de dados, à análise dos dados e aos resultados. 
Método UEP aplicado à pequena empresa fabril: uma relação custo/benefício favorável Marluce Lembeck, Rodney Wernke

\section{APRESENTAÇÃO E DISCUSSÃO DOS RESULTADOS}

As próximas seções descrevem os passos percorridos para atingir o objetivo da pesquisa, além de descreverem os principais resultados obtidos.

\subsection{Divisão da fábrica em postos operativos e cálculo do custo/hora}

Nessa etapa, foram identificados os postos operativos (POs) da fábrica, que poderiam ser uma máquina, um posto de trabalho manual ou o conjunto deles. No caso em tela, procurou-se fazer os postos operativos coincidirem com uma máquina com a finalidade de facilitar a visualização e a determinação dos índices de custos. Então, depois de analisadas as operações executadas em cada um dos setores fabris, foram identificados 42 (quarenta e dois) postos operativos.

Posteriormente à definição dos postos operativos, passou-se à fase de cálculo do custo/hora (em $\mathrm{R} \$$ ) dos $\mathrm{POs}$, abrangendo os gastos incorridos para o funcionamento de cada um destes. Com a ajuda do gestor da produção, foi apurado o valor total ( $R$ \$ $35.443,27)$ dos custos fabris de cada posto no mês utilizado como base para a pesquisa e determinado o número de horas do expediente mensal desses POs. Então, fez-se a divisão do (1) custo mensal total (em $R \$$ ) de cada posto operativo pela (2) quantidade de horas produtivas no posto de trabalho. Com isso, encontrou-se o (3) custo/hora (em $\mathrm{R} \$$ ) de cada posto operativo (3=1/2) considerando folha de pagamentos, depreciação do maquinário fabril, energia elétrica da produção, manutenção industrial, aluguel do prédio industrial e material de consumo.

\subsection{Tempo de passagem dos produtos pelos postos operativos}

O cálculo do esforço de produção está fundamentado no tempo gasto para produzir os itens em cada posto operativo. Destarte, foi necessário levantar os "tempos de passagem" de cada integrante do mix comercializado pela empresa pesquisada com auxílio dos encarregados de cada setor fabril. Entretanto, conforme destacado anteriormente, um dos possíveis pontos fracos dos métodos de custeio que utiliza o 
critério "tempo" (como o UEP e o TDABC) reside na determinação dos tempos de produção.

Então, para obter um melhor diagnóstico da realidade produtiva da fábrica, o cálculo utilizado levou em conta a produção total do mês investigado e englobou as paradas de produção normais (ou eventuais) oriundas de troca de matérias-primas, ajustes de máquinas, quedas de energia elétrica etc. Assim, considerou-se que a produção teria alguns fatores que impedem a fabricação ininterrupta, o que refletiria melhor a realidade industrial diagnosticada. Por isso, em vez de "cronometrar" a produção de cada item, foi apurada a quantidade média fabricada (em número de peças) por dia de cada produto. É importante destacar que referido procedimento não tem a capacidade de eliminar completamente as eventuais falhas na definição dos tempos de passagem, de vez que alguns fatores que implicam perda de tempo eventualmente podem não ter sido computados. Entretanto, foi adotado por ser mais representativo da realidade fabril do que a cronometragem do tempo "ideal".

Em seguida, dividiu-se tal quantidade pelo número de horas do expediente diário de cada posto operativo, obtendo-se a produção por hora. Na sequência, dividiuse "1" por essa quantidade fabricada por hora para apurar o tempo de passagem (em fração de horas) dos produtos em cada posto operativo. Os resultados obtidos com esse procedimento evidenciaram que os produtos do mix abrangido têm tempos de produção distintos nos POs que percorrem para serem fabricados, conforme o grau de dificuldade que lhes é inerente.

\subsection{Determinação do produto-base e cálculo do valor do custo-base (em $\mathbf{R} \$$ )}

Nessa etapa de operacionalização do método de custeio UEP, fez-se a escolha do produto-base que, segundo Bornia (2009), pode ser aquele que represente a estrutura produtiva da fábrica da maneira mais adequada possível (passando por grande número de POs) ou o produto mais fabricado (para facilitar a análise comparativa da consistência dos valores apurados para cada item). 
No caso da empresa pesquisada, o produto-base escolhido foi 0 "Pij.A.Print/Blusa" porque, além de ser um dos produtos de maior faturamento, sua produção exige a passagem por vários postos de trabalho. Com isso, permitiu um melhor entendimento e visualização para os usuários do método acerca das unidades equivalentes em UEP que foram apuradas para os demais produtos.

Para determinar o valor do custo-base (em $\mathrm{R} \$$ ), foi necessário multiplicar o (i) custo/hora $(\mathrm{R} \$)$ do PO pelo respectivo (ii) tempo de passagem (em horas) desse produto nos postos utilizados em sua fabricação. Em seguida, fez-se o somatório do valor resultante da multiplicação de todos os postos para apurar o valor (em $R \$$ ) do custo do produto-base, conforme exemplificado detalhadamente na Tabela 1.

Tabela 1

Foto-índice do produto-base: Pij.A.Print/Blusa

\begin{tabular}{|c|c|c|c|}
\hline Postos Operativos & $\begin{array}{c}\text { Tempo de } \\
\text { passagem (h) }\end{array}$ & $\begin{array}{l}\text { Custo por } \\
\text { hora }(\mathbf{R} \$)\end{array}$ & $\begin{array}{l}\text { Foto-índice do } \\
\text { prod. base (R\$) }\end{array}$ \\
\hline Overl. Nissin & 0,05000 & 0,4622 & 0,02311 \\
\hline Overl. Pt. Cad.Tr. Dup. & 0,06667 & 12,2998 & 0,81999 \\
\hline 12 Ag. Reb. Elást. & - & 0,8824 & - \\
\hline Reta Mec. & 0,19333 & 0,4996 & 0,09658 \\
\hline Domest. Preg. Bot. & 0,02667 & 0,4809 & 0,01282 \\
\hline Caseadeira & 0,02500 & 1,2092 & 0,03023 \\
\hline Galon. KS-1 & 0,04167 & 3,8632 & 0,16097 \\
\hline Outros... & $\ldots$ & $\ldots$ & \\
\hline Total & 0,50000 & - & 1,73094 \\
\hline
\end{tabular}

Nota. Fonte: Elaborada pelos autores

Assim, no caso exemplificado, apurou-se o valor de $R \$ 1,73094$ como foto-índice do produto base, tendo este sido utilizado na etapa seguinte de implementação.

\subsection{Cálculo dos potenciais produtivos}

Nesta etapa, foi realizado o cálculo dos potenciais produtivos dos postos operativos (POs), o que permite conhecer a capacidade instalada de produção em termos de "UEPs por hora" em cada etapa fabril. Este cálculo foi alcançado a partir da 
divisão do custo/hora (em $R \$$ ) de cada PO pelo custo do produto-base (em $R \$$ ), conforme evidenciado na Tabela 2, que apresenta somente alguns postos por restrição de espaço.

Tabela 2

Potencial produtivo dos postos operativos

\begin{tabular}{lccc}
\hline \multicolumn{1}{c}{ Postos Operativos } & $\begin{array}{c}\text { Custo por } \\
\text { hora (R\$) }\end{array}$ & $\begin{array}{c}\text { Foto-índice do } \\
\text { prod. base (R\$) }\end{array}$ & $\begin{array}{c}\text { Potencial } \\
\text { produt. (UEP/h) }\end{array}$ \\
\hline Overl. Nissin & 0,4622 & 1,7309 & 0,26704 \\
Overl. Pt. Cad. Tr. Dup. & 12,2998 & 1,7309 & 7,10586 \\
12 Ag. Reb. Elást. & 0,8824 & 1,7309 & 0,50978 \\
Reta Mec. & 0,4996 & 1,7309 & 0,28862 \\
Domest. Preg. Bot. & 0,4809 & 1,7309 & 0,27783 \\
Caseadeira & 1,2092 & 1,7309 & 0,69858 \\
Galon.KS-1 & 3,8632 & 1,7309 & 2,23186 \\
Galon. Eletr. Refil. & 3,2863 & 1,7309 & 1,89855 \\
Reta Mec.-2 & 6,0748 & 1,7309 & 3,50956 \\
Outros... & $\ldots$ & $\ldots$ & $\ldots$ \\
\hline
\end{tabular}

Nota. Fonte: Elaborada pelos autores

Pelos resultados apurados na Tabela 2, verifica-se que os postos operativos possuem distintas capacidades de produção em termos de UEPs por hora. Como os postos operativos representam as fases pelas quais os produtos devem passar para serem fabricados, constata-se que medidas para diminuir tal problema tornam-se imprescindíveis no intuito de maximizar a produção final do empreendimento. O ideal seria que houvesse um fluxo contínuo de produção para não gerar os chamados "gargalos produtivos".

\subsection{Determinação dos equivalentes dos produtos em UEP}

O passo seguinte consistiu em calcular os equivalentes dos produtos em UEP. Essa determinação acontece com o consumo, por parte de cada item fabricado, do potencial produtivo do $\mathrm{PO}$ à medida que passam pelos mesmos. Ou seja, de acordo com o tempo de passagem pelo posto operativo, o produto vai consumir (ou absorver) 
parte do potencial de produção do posto. Assim, ao multiplicar o tempo de passagem do produto pela UEP/hora do posto operativo, encontra-se a quantidade de UEPs utilizada pelo produto no posto (ou o uso da capacidade instalada).

A soma das UEPs consumidas pelo produto, de todos os postos em que passar, irá determinar a quantidade total de UEPs para cada um destes, conforme exposto na Tabela 3 para o produto "Pij. A. Print./Blusa" (a título de exemplo).

Tabela 3

Equivalente em UEP do produto Pij. A. Print./Blusa

\begin{tabular}{lccc}
\hline \multicolumn{1}{c}{ Postos Operativos } & $\begin{array}{c}\text { Tempo de } \\
\text { passagem }(\mathbf{h})\end{array}$ & $\begin{array}{c}\text { Potencial } \\
\text { produt. (UEP/h) }\end{array}$ & $\begin{array}{c}\text { Equiv. em UEP } \\
\text { do produto }\end{array}$ \\
\hline Overl. Nissin & 0,05000 & 0,26704 & 0,01335 \\
Overl. Pt. Cad. Tr. Dup. & 0,06667 & 7,10586 & 0,47372 \\
12 Ag. Reb. Elást. & - & 0,50978 & - \\
Reta Mec. & 0,19333 & 0,28862 & 0,05580 \\
Domest. Preg. Bot. & 0,02667 & 0,27783 & 0,00741 \\
Caseadeira & 0,02500 & 0,69858 & 0,01746 \\
Galon. KS-1 & 0,04167 & 2,23186 & 0,09299 \\
Outros... & $\ldots$ & $\ldots$ & $\ldots$ \\
Total & - & - & 1,00000 \\
\hline
\end{tabular}

Nota. Fonte Elaborada pelos autores.

Para avaliar a adequação dos valores calculados como equivalente em UEPs de todos os produtos fabricados, é interessante realizar uma análise de consistência. Para tanto, com o auxílio do responsável pela produção, foram conferidos os valores em UEPs apurados do mix fabricado no mês, considerando-se a premissa de que a UEP representa o esforço fabril desenvolvido em cada produto. Consequentemente, os produtos que exigissem processamento diferente (em máquinas e tempos de passagem) deveriam ter equivalentes em UEPs distintos.

Por exemplo: uma peça do produto "Pij. A. Print./Blusa" exige mais esforços de produção (por conter mais partes, detalhes, adereços etc.) do que uma unidade do "Pij. A. Print./Calça". Com isso, o valor equivalente em UEP de uma blusa desse produto $(1,000000$ UEP) deve ser maior que o valor equivalente em UEP de uma calça do 
mesmo conjunto (cujo equivalente totalizou 0,09173UEP). Com isso, é correto considerar que a calça custará apenas $9,173 \%$ do valor de custo de transformação da blusa desse conjunto (exceto a matéria-prima consumida). Após concluída essa análise, verificou-se que os valores calculados se coadunaram com a realidade do processo de fabricação pesquisado. Tal procedimento comparativo foi efetuado para todos os demais itens produzidos, não tendo sido registrada nenhuma inconsistência na opinião do gerente de produção/proprietário da empresa.

Quanto ao fato de utilizar a opinião do gestor sobre as equivalências dos produtos em termos de esforço de produção, tal procedimento está coerente com a análise de consistência que deve ser efetuada sobre esses valores, de vez que o entendimento a respeito (Bornia, 2009; Souza \& Diehl, 2009; Allora \& Oliveira, 2010; Wernke et al. 2013, entre outros) é de que os pareceres efetivamente mais confiáveis sobre a pertinência dos UEPs equivalentes por produto são originários dos gestores fabris. Ou seja, estes teriam melhores condições para identificar possíveis distorções causadas por erros relacionados ao tempo de passagem nos postos operativos, entre outras possibilidades de equívocos.

Nesse rumo, Martins e Rocha (2010) registram que "nenhuma informação de custo, qualquer que seja o método de custeio, substitui o julgamento e o bom-senso das pessoas que analisam e decidem". Referidos autores comentam que o melhor método será aquele que mais ajude a resolver o problema que se apresente em determinada situação, induzindo os gestores a tomar decisões adequadas em cada caso. "Isso permite constatar que o uso deste ou daquele método de custeio para fins gerenciais depende, também, do modelo decisório dos gestores".

\subsection{Mensuração da produção total de UEPs no período}

Nesta etapa, foi realizada a mensuração da produção total da fábrica, em termos de UEPs produzidas no período analisado. Esse valor foi apurado pela multiplicação das (i) unidades físicas fabricadas de cada produto pela (ii) quantidade de UEPs que os mesmos representam individualmente. No caso da empresa em lume, no 
mês pesquisado, a produção da fábrica totalizou 2.210,17537 UEPs, como exposto resumidamente na Tabela 4.

Tabela 4

Quantidade de UEPs produzidas no mês

\begin{tabular}{lccc}
\hline \multicolumn{1}{c}{ Produtos } & $\begin{array}{c}\text { Produção } \\
\text { do mês (unid.) }\end{array}$ & $\begin{array}{c}\text { Equivalente em } \\
\text { UEP/produto }\end{array}$ & $\begin{array}{c}\text { Produção total } \\
\text { de UEPs no mês }\end{array}$ \\
\hline Pij. A. Print/Blusa & 92 & 1,00000 & 92,00000 \\
Pij. A. Print/Calça & 92 & 0,09173 & 8,43935 \\
Pij. Delicata & 43 & 0,66074 & 28,41191 \\
Camisão Delicata & 88 & 0,66074 & 58,14531 \\
Pij. Delicata Aberto & 88 & 0,09173 & 8,07242 \\
Outros... & $\ldots$ & $\ldots$ & $\ldots$ \\
\hline Totais & 7.361 & - & $2.210,17537$ \\
\hline
\end{tabular}

Nota. Fonte: Elaborada pelos autores.

Convém salientar que a linha "Outros..." da Tabela 4 representa os demais produtos fabricados e abrangidos pelo estudo, mas que não estão expostos neste texto pela limitação de espaço.

\subsection{Cálculo do custo de transformação dos produtos}

Para estipular quanto custa para ser fabricado cada produto, mais especificamente no que tange à transformação das matérias-primas em produtos prontos, é necessário calcular inicialmente o valor (em $R \$$ ) da UEP no período em foco. Esse valor da UEP é determinado a partir da divisão do (a) custo total mensal de transformação (em $\mathrm{R} \$$ ) pela (b) quantidade de UEPs fabricadas nesse período.

Nesse caso, considerou-se que os custos totais de fabricação do período em estudo totalizaram o valor de $R \$ 35.443,27$, representados pelos fatores enfocados anteriormente (folha de pagamentos, depreciações, manutenção, energia elétrica etc.). No mesmo período, produziu-se uma quantidade de produtos cujo valor equivalente totalizou 2.210,17537 UEPs (conforme evidenciado na Tabela 4). Com base nesses 
dados, o valor (em $\mathrm{R} \$$ ) da UEP no mês foi apurado nos moldes do representado na Tabela 5.

Tabela 5

Valor da UEP no mês

\begin{tabular}{lcc}
\hline \multicolumn{1}{c}{ Itens } & Valores & \% do Custo fabril total \\
\hline 1) Total gasto no mês (em R\$) & $35.443,27$ & $100,00 \%$ \\
2) Produção do mês em UEPs & $2.210,17537$ & - \\
$(3=1 / 2)$ Valor da UEP (em R\$) do período & 16,03641 & - \\
\hline
\end{tabular}

Nota. Fonte: Elaborada pelos autores.

Nesse ponto, tendo em vista o valor de UEP do período apurado na Tabela 5 e com a definição anterior do equivalente em UEP de cada produto (nos moldes do procedimento exemplificado na Tabela 3), dispunha-se de um conjunto de dados suficiente para apurar o custo de transformação (em $R \$$ ) dos produtos fabricados no mês.

A Tabela 6 apresenta os custos de transformação de alguns produtos (a título de exemplo), obtidos a partir da multiplicação do equivalente em UEP dos produtos pelo valor monetário da UEP apurado no mês enfocado ( $R \$ 16,03641)$.

Tabela 6

Custo de transformação (unitário e total) por produto

\begin{tabular}{lccccc}
\hline \multicolumn{1}{c}{ Produtos } & $\begin{array}{c}\text { Equivalente em } \\
\text { UEP/produto }\end{array}$ & $\begin{array}{c}\text { Valor da UEP } \\
\text { no mês (R\$) }\end{array}$ & $\begin{array}{c}\text { Custo unitário de } \\
\text { Transformar (R\$) }\end{array}$ & $\begin{array}{c}\text { Produção do } \\
\text { mês (unid.) }\end{array}$ & $\begin{array}{c}\text { Custo total } \\
\text { alocado (R\$) }\end{array}$ \\
\hline Pij. A. Print/Blusa & 1,00000 & 16,03641 & 16,03641 & 92 & $1.475,35$ \\
Pij. A. Print/Calça & 0,09173 & 16,03641 & 1,47105 & 92 & 135,34 \\
Pij. Delicata & 0,66074 & 16,03641 & 10,59593 & 43 & 455,63 \\
Camisão Delicata & 0,66074 & 16,03641 & 10,59593 & 88 & 932,44 \\
Pij. Delicata Aberto & 0,09173 & 16,03641 & 1,47105 & 88 & 129,45 \\
Outros... & $\ldots$ & $\ldots$ & $\ldots$ & - & - \\
\hline Totais & - & - & - & 7.361 & $35.443,27$ \\
\hline
\end{tabular}

Nota. Fonte: Elaborada pelos autores. 
Ou seja, o valor total do custo de transformação mensal $(\mathrm{R} \$ 35.443,27)$ foi integralmente alocado às 7.361 unidades produzidas no período abrangido.

\subsection{Análise do desempenho dos produtos comercializados}

Com a planilha elaborada, a administração da fábrica passou a dispor de informações mais consistentes quanto ao custo de transformação dos produtos fabricados, se comparada à metodologia anteriormente utilizada. Ou seja, passaram a ser calculados pelo método UEP, em vez da mera divisão dos gastos fabris do mês pelo volume produzido no período (independentemente das características do produto), o que acarretava valores incoerentes porque teriam o mesmo valor unitário, independentemente dos recursos despendidos na fabricação destes. Em razão disso, os gestores passaram a contar com informações úteis para conhecer a lucratividade dos itens fabricados, conforme descrito a seguir.

A primeira informação importante diz respeito ao "custo total unitário de cada produto" (custo de matérias-primas e de transformação). Como a empresa já dispunha do custo relacionado ao consumo de matérias-primas por produto e passou a contar também com o custo de transformação obtido pelo método UEP, também foi possível conhecer o custo total por unidade fabricada. Assim, conforme descrito na Tabela 7, os dados disponíveis facultaram apurar a margem de contribuição unitária "fabril" de cada produto, tanto em valor monetário $(\mathrm{R} \$)$ quanto na forma percentual (\%). 
Método UEP aplicado à pequena empresa fabril: uma relação custo/benefício favorável Marluce Lembeck, Rodney Wernke

Tabela 7

Margem de contribuição unitária e total do produto: Pij.A.Print/Blusa+Calça (conjunto)

\begin{tabular}{lcccc}
\hline \multicolumn{1}{c}{ Itens } & $\begin{array}{c}\text { Valores } \\
\text { unit. (R\$) }\end{array}$ & $\begin{array}{c}\text { Percentual do } \\
\text { Preço de Venda (\%) }\end{array}$ & $\begin{array}{c}\text { Quantidade } \\
\text { Vendida/mês }\end{array}$ & $\begin{array}{c}\text { Valores } \\
\text { totais (R\$) }\end{array}$ \\
\hline (+) Preço de venda & 95,90 & $100,00 \%$ & 92 & $8.822,80$ \\
(-) Custo de matérias-primas (ficha técnica) & 41,11 & $42,87 \%$ & 92 & $3.782,22$ \\
(-) Tributos sobre vendas (5,5\%) & 5,27 & $5,50 \%$ & 92 & 485,25 \\
(-) Comissões sobre vendas (10\%) & 1,92 & $2,00 \%$ & 92 & 176,46 \\
(=) Margem de contribuição tradicional & 47,60 & $49,63 \%$ & 92 & $4.378,87$ \\
(-) Custo fabril apurado pelo método UEP & 17,51 & $18,26 \%$ & 92 & $1.610,69$ \\
(=) Margem de contribuição fabril & 30,09 & $31,38 \%$ & 92 & $2.768,18$ \\
\hline
\end{tabular}

Nota. Fonte: Elaborada pelos autores

No caso do produto "Pij. A. Print/Blusa+Calça (conjunto)", constatou-se que o peso do custo de transformação era de $18,26 \%$ do preço de venda $(R \$ 17,51 / R \$$ 95,90 x 100). Caso esse valor não fosse computado, ter-se-ia margem de contribuição unitária percentual de 49,63\% ( $R \$ 47,60 / R \$ 95,90 \times 100)$, contra 31,38\% ( $R \$ 30,09 /$ $\mathrm{R} \$ 95,90 \times 100)$, se calculado nos moldes da margem de contribuição "fabril". Embora não seja objetivo desta pesquisa comparar o Custeio Variável (Margem de Contribuição) com o UEP, visto que envolvem concepções distintas quanto ao tratamento dos custos fixos (ou indiretos), essa influência maior ou menor dos custos de transformação no resultado final dos produtos somente enaltece a importância que os administradores devem atribuir ao cálculo desses custos de forma tecnicamente consistente. Tal fator pode representar alterações significativas na rentabilidade atribuída aos produtos que, se não forem detectadas nas planilhas de custos, ocasionam decisões inadequadas do ponto de vista gerencial, principalmente em termos da avaliação do desempenho da lucratividade dos produtos comercializados.

Como expresso na Tabela 7, foi utilizada neste estudo a expressão "Margem de Contribuição Fabril” para melhor designar a lucratividade de cada produto. Cabe ressaltar que essa forma de cálculo diverge da literatura contábil, que defende que não se deve computar o custo unitário de fabricação no cálculo da margem de contribuição. Porém, os custos de transformação têm um montante significativo, e o consumo de 
recursos é distinto de um produto para o outro. Não computá-los na análise de desempenho, prejudicará a qualidade informacional quanto à lucratividade dos itens avaliados. Por isso, nesta pesquisa, a margem de contribuição "fabril" foi empregada para determinar a efetiva lucratividade unitária dos produtos fabricados, conforme preconizado por Anthony e Govindarajan (2002).

Depois de mensurar a margem de contribuição "fabril" por unidade, foi possível determinar a "Margem de Contribuição Fabril Total" do período, segregada por produto. Para tanto, no caso do produto apresentado na Tabela 7, bastou multiplicar as quantidades comercializadas (92 unidades) pela respectiva contribuição unitária ( $R$ \$ 30,09 ) para chegar à margem de contribuição total de $R \$ 2.768,18$ para esse produto.

Outra forma de analisar o desempenho dos produtos diz respeito ao comparativo do "peso" de cada posto operativo no valor (em $\mathrm{R} \$$ ) do custo de transformação unitário de cada item, conforme exposto na Tabela 8 para dois produtos, como exemplo.

Tabela 8

Custo de transformação dos produtos por posto operativo

\begin{tabular}{lrrrrrr}
\hline & \multicolumn{3}{c}{ Pij.A.Print/Blusa } & \multicolumn{3}{c}{ Pij.M.Amor M.Curta/Blusa } \\
Postos Operativos & Equiv. em UEP & C. Transf. unit. R\$ & $\%$ do total & Equiv. em UEP & C. Transf. unit. R\$ & $\%$ do total \\
\hline Overl. Nissin & 0,01335 & 0,21412 & $1,34 \%$ & 0,01335 & 0,21412 & $2,02 \%$ \\
Overl. Pt. Cad. Tr. & 0,47372 & 7,59683 & $47,37 \%$ & 0,47372 & 7,59683 & $71,70 \%$ \\
Reta Mec. & 0,05580 & 0,89481 & $5,58 \%$ & 0,05580 & 0,89481 & $8,44 \%$ \\
Domest. Preg. Bot. & 0,00741 & 0,11881 & $0,74 \%$ & 0,00741 & 0,11881 & $1,12 \%$ \\
Caseadeira & 0,01746 & 0,28007 & $1,75 \%$ & 0,01746 & 0,28007 & $2,64 \%$ \\
Galon. KS-1 & 0,09299 & 1,49129 & $9,30 \%$ & 0,09299 & 1,49129 & $14,07 \%$ \\
Reta Mec.-2 & 0,33926 & 5,44048 & $33,93 \%$ & - & - & $0,00 \%$ \\
\hline Total & 1,00000 & 16,03641 & $100,00 \%$ & 0,66074 & 10,59593 & $100,00 \%$ \\
\hline
\end{tabular}

Nota. Fonte: Elaborada pelos autores.

O produto "Pij. A. Print/Blusa" passa por sete Postos Operativos, mas o "peso" maior, em termos do valor do custo de transformação, está vinculado à passagem pelo P. O. "Overl. Pt. Cad. Tr. Dup", visto que o custo de R $\$ 7,59683$ representa 47,37\% do 
custo unitário total deste item $(R \$ 16,03641)$. O segundo maior valor diz respeito ao $P$. O. "Reta Mec.-2", com R $\$ 5,44048$ (ou 33,93\% do custo de transformação do produto). No que concerne ao "Pij. M. Amor M. Curta/Blusa", a fabricação deste requer a passagem por seis dos sete postos pelos quais o produto anterior passava. Em decorrência disso, mesmo que os tempos de passagem nesses seis postos sejam iguais, seu custo unitário final é menor ( $R \$ 10,59593)$ por não contar com o custo relativo ao P. O. "Reta Mec.-2". Destarte, a passagem deste produto pela máquina "Overl. Pt. Cad. Tr. Dup." custará o mesmo que custou para o outro produto, mas terá uma participação percentual no custo final maior (71,70\%). Além disso, o segundo posto operativo que mais influenciou no custo unitário foi a "Galon.KS-1", visto que esta etapa produtiva custava $R \$ 1,49129$ por peça fabricada (14,07\%).

Essa possibilidade de avaliar a lucratividade e identificar com facilidade a composição do custo fabril de cada unidade fabricada é corroborada por Kuhn, Francisco e Kovaleski (2011) e Wernke et al. (2015). Referidos autores comentam que uma das vantagens do método UEP é que permite ter clareza de quais produtos podem gerar mais rentabilidade e quais geram lucro efetivamente, mesmo que a empresa possua, em seu mix de comercialização, centenas de produtos. Então, após conhecido qual produto tem menor potencial de ganho e geração efetiva de resultado, podem-se desenvolver trabalhos de melhorias com foco na otimização do resultado do período.

\subsection{Discussão dos resultados}

O conteúdo das seções anteriores conduz, basicamente, a dois resultados que merecem ser salientados: o volume de informações úteis para o gestor da pequena fábrica de confecções proporcionadas pelo método UEP e a possibilidade de implementar tal metodologia de custeamento sem dispêndio elevado de recursos.

No que concerne ao primeiro aspecto, as fases percorridas para aplicar o UEP no contexto da indústria em tela evidenciaram um rol de informações que podem ser muito importantes para aprimorar a gestão da entidade. Nesse caso, é pertinente enfatizar a possibilidade de conhecer o potencial produtivo de cada posto operativo, a 
determinação do equivalente em UEP de cada produto, o volume total de UEPs fabricadas no período, a facilidade para atualizar mensalmente o valor da UEP, o cálculo do custo de transformação unitário e o total para cada produto, a mensuração da margem de contribuição "fabril" unitária e total dos itens comercializados e o percentual de participação dos postos operativos no custo do produto. Esses resultados corroboram os benefícios informativos enaltecidos em livros e artigos que trataram desse método, como Wernke et al. (2015), Wernke, Junges e Cláudio (2012), Bornia (2009), Souza e Diehl (2009), Schultz, Silva e Borgert (2008) entre outros.

O segundo aspecto a destacar refere-se ao gasto para implementar e operacionalizar o método UEP. Há várias menções na literatura sobre as dificuldades associadas à implementação e à operacionalização de métodos de custeio mais complexos, como é o caso do UEP (Pereira, 2015; Souza, 2014; Fontoura, 2013; Martins \& Rocha, 2010; Souza \& Diehl, 2009; Kaplan \& Anderson, 2004). Essas argumentações focam especialmente a necessidade de elevados recursos financeiros, humanos e organizacionais para implementação e manutenção, o que faria com que fossem adequados somente para companhias maiores e que se disponham a investir elevado montante de recursos para esta finalidade.

Entretanto, no caso em tela, essa realidade não se fez presente. A operacionalização do UEP por intermédio de planilha Excel permitiu ter agilidade na elaboração do instrumento utilizado para mensurar custos, bem como facilitou a atualização posterior a cada mês ou período desejado pelo gestor. Nesse contexto, não houve custo com software específico nem com consultorias especializadas, visto que a elaboração da planilha fazia parte de orientação de trabalho de conclusão de curso realizada por um dos autores. Mesmo que não houvesse esse "auxílio externo", o detalhamento evidenciado nas seções precedentes possibilita adaptar facilmente esse modelo de planilha a outros contextos, notadamente em empresas fabris de portes assemelhados, sem despender muito dinheiro com essa finalidade.

Além disso, como o equivalente em UEP tende a se manter "estável", desde que mantida a estrutura fabril e que os tempos considerados de fabricação dos itens 
permaneçam semelhantes, restará ao proprietário atualizar periodicamente os valores relativos aos gastos industriais e às quantidades produzidas de cada item. Dessa forma, como o próprio gestor/proprietário poderá fazer essas atualizações, não haverá gasto significativo para operacionalizar a utilização desse instrumento nos próximos meses (além do tempo deste), o que reforça a relação custo/benefício de utilizar tal planilha. Ou seja, o dispêndio com a folha de pagamentos poderá ser obtido com o contador, enquanto que o valor da energia elétrica está disponível na fatura mensal. Os valores de material de consumo e manutenção fabril podem ser "estimados" ou obtidos nos controles internos da entidade, e a depreciação fabril permanecerá no mesmo patamar se não houver aquisição de maquinário.

O segundo fator a atualizar periodicamente se relaciona com as quantidades físicas fabricadas, necessárias para apurar o total de UEPs produzidas no período, conforme exemplificado na Tabela 6. Ao se dispor do volume físico de produção por produto, basta multiplicar pelo respectivo equivalente em UEP para apurar a quantidade de UEPS fabricadas, cujo resultado servirá para determinar o novo valor monetário da UEP (em R\$), como exposto na Tabela 7 em seção anterior. O valor atualizado da UEP $(\mathrm{R} \$)$ fundamentará os cálculos dos novos custos de transformação, visto que basta multiplicá-lo pelo equivalente em UEP dos produtos para atualizá-los monetariamente. Por outro lado, a inserção de outros produtos ou de novas máquinas de produção requer que sejam adicionadas "linhas" e/ou "colunas" na mesma planilha Excel. Então, para essa finalidade, basta repetir as mesmas fórmulas, que representam os passos citados nas tabelas expostas nas seções anteriores.

Como visto, ao contrário da opinião muito disseminada na literatura de custos, nesse tipo e porte de empresa não é necessário despender montante significativo de recursos para aproveitar os benefícios informativos que o método UEP proporciona. 


\section{CONCLUSÕES E RECOMENDAÇÃO PARA TRABALHOS FUTUROS}

O artigo pretendeu responder questão de pesquisa ligada à possibilidade de que o método UEP seja uma opção viável para empresas industriais de pequeno porte, sem despender montante elevado de recursos para implementar e operacionalizar essa forma de custeio. Nessa direção, o estudo visava avaliar a possibilidade de mensurar os custos de transformação do mix comercializado por uma pequena fábrica de confecções underwear utilizando o método UEP de modo economicamente viável quanto à implantação e operacionalização nesse porte de empresa. Acerca disso, os autores entendem que tal pergunta foi convenientemente respondida e o objetivo foi atingido, visto que, nas seções precedentes, foram detalhados os passos necessários para elaborar e atualizar uma planilha de custos baseada no UEP sem implicar gasto relevante, e foram comentadas as principais informações disponibilizadas pela ferramenta sugerida.

O gestor da fábrica em tela não utilizava uma metodologia consistente tecnicamente para definição dos custos de transformação dos seus produtos. Existiam, portanto, incertezas quanto aos percentuais de lucratividade de cada item fabricado, tendo em vista que eram apenas apurados os custos relacionados com matérias-primas consumidas e estimado, superficialmente, o custo de produção pela divisão dos custos fabris totais pela quantidade de peças produzidas no mês, independentemente de tamanhos, formatos, tempos de produção etc.

Entretanto, a mensuração de custos pelo método UEP permitiu conhecer, entre outras informações gerenciais, o valor do custo/hora em cada posto operativo; a capacidade instalada de produção, em termos do potencial produtivo dos postos operativos em UEPs por hora; a mensuração da produção total de UEPs do mês, o que possibilita comparar a produtividade entre os períodos; o custo unitário de transformação de cada produto, revelando o esforço produtivo (em $\mathrm{R} \$$ ) que os itens fabricados consumiram no mês a cada unidade elaborada; o valor do custo de transformação total alocado/atribuído aos produtos em virtude da produção física 
respectiva destes no período, bem como foi possível conhecer a lucratividade de cada produto e o "peso" do custo unitário de transformação de cada posto operativo. Ao conhecer esses valores, o gestor passou a contar com informações mais consistentes para analisar a lucratividade de seus produtos e respectivas linhas de produção, minimizando incertezas acerca da performance desses objetos de custeio.

Além do aspecto da contribuição prática em termos das informações propiciadas a partir dos resultados sintetizados nos parágrafos anteriores, entende-se que esta pesquisa contribuiu também no sentido de:

a) Mostrar que é possível utilizar o método UEP em fábrica de pequeno porte, de forma economicamente viável. Isso contradiz diversas menções na literatura sobre a necessidade de dispêndios elevados para implementar e operacionalizar um método de custeio mais sofisticado, o que inviabilizaria a utilização nas empresas menores.

b) Evidenciar estudo com enfoque mais "prático" que possibilite auxiliar os gestores a implementar essa forma de custeio, corroborando o entendimento de Baldvinsdottir et al. (2010) e Lukka (2010) acerca da necessidade de maior número de estudos com essa ênfase.

Apesar dos diversos benefícios informativos proporcionados pelo método UEP, da mesma forma que outros métodos, este possui várias limitações conforme destacado na revisão da literatura em seção específica. Desse modo, no caso da empresa pesquisada, é válido salientar que a qualidade das informações gerenciais obtidas estava vinculada à exatidão dos tempos de passagem atribuídos para cada produto nos postos operativos. Se os tempos inseridos na planilha de custos não correspondessem à realidade fabril enfocada, o aspecto qualitativo dos resultados oriundos automaticamente seria afetado.

Como sugestão para trabalhos futuros, recomenda-se que sejam priorizados estudos que: (I) evidenciem as possibilidades de mensuração de indicadores não financeiros que o método UEP permite apurar nesse mesmo porte de indústria; (ii) 
verifiquem a possibilidade de aplicar outros métodos de custeio (como TDABC ou ABC) de forma assemelhada ao proposto nesta pesquisa; e (iii) enfoquem as limitações apontadas acerca do UEP no sentido de aprimorar essa metodologia de custeamento ou para expandir a aplicação para outros segmentos empresariais.

\section{REFERÊNCIAS}

Allora, F. (1988). Controle de produção unificado e o computador. São Paulo: Pioneira.

Allora, F., \& Allora V. (1995). UP: Unidade de medida da produção. São Paulo: Pioneira.

Allora, V., \& Oliveira, S. E. (2010). Gestão de custos: metodologia para a melhoria da performance empresarial. Curitiba: Juruá.

Anthony, R. N., \& Govindarajan, V. (2002). Sistemas de controle gerencial. São Paulo: Atlas.

Baldvinsdottir, G., Mitchell, F., \& Nørreklit, H. (2010). Issues in the relationship between theory and practice in management accounting. Management Accounting Research, 21(2), 79-82.

Bornia, A. C. (2009). Análise gerencial de custos: aplicação em empresas modernas (2a ed.). São Paulo: Atlas.

Cambruzzi, D., Balen, F. V., \& Morozini, J. F. (2009). Unidade de esforço de produção (UEP) como método de custeio: implantação de modelo em uma indústria de laticínios. ABCustos, Associação Brasileira de Custos, 4(1), 84-103.

De La Villarmois, O., \& Levant, Y. (2011). From adoption to use of a management control tool: case study evidence of a costing method. Journal of Applied Accounting Research, 12(3), 234-259.

Ferrari, M. J. (2012). Custeio de serviços baseados em unidade de medida de produção. (Dissertação de Mestrado). Universidade Federal de Santa Catarina, Florianópolis, SC, Brasil.

Fontoura, F. B. B. da. (2013). Gestão de custos: uma visão integradora e prática dos métodos de custeio. São Paulo: Atlas.

Gantzel, G., \& Allora, V. (1996). Revolução nos custos. Salvador: Casa da Qualidade. 
Gervais, M. (2006). Les conditions de la fiabilité des coûts dans l'utilisation de la méthode UVA (méthode des unités de valeur ajoutée). Revue Finance Contrôle Stratégie, 9 (2), 225-258.

Gervais, M. (2009). Contrôle de gestion (9a ed.). Economica: Paris.

Gervais, M., \& Levant, Y. (2007). Comment garantir l'homogénéité globale dans la méthode UVA? Deux études de cas. Revue Finance Contrôle Stratégie, 10(3), 4373.

Guerreiro, R. (2001). Estruturação de sistemas de custos para a gestão da rentabilidade. São Paulo: Atlas.

Kaplan, R. S., \& Anderson, S. R. (2004). Time-Driven Activity-Based Costing. Harvard Business Review, 82(11), 131-138.

Levant, Y., \& De La Villarmois, O. (2004). Georges Perrin and the GP cost calculation method: the story of a failure. Accounting, Business \& Financial History, 2(14), 151181.

Levant, Y., \& Zimnovitch, H. (2013). Contemporary evolutions in costing methods: understanding these trends through the use of equivalence methods in France. Accounting History, 18(1), 51-75.

Luiz, G., Gasparetto, V., Lunkes, R. J., \& Schnorrenberger, D. (2014). Utilização do Método da Unidade de Esforço de Produção (UEP): estudo em uma empresa de cosméticos. Revista ABCustos, Associação Brasileira de Custos, 9(1), 29-47.

Lukka, K. (2010). The roles and effects of paradigms in accounting research. Management Accounting Research, 21(2), 110-115.

Malaquias, R. F., Giachero, O. S., Costa, B. E. da, \& Lemes, S. (2007). Método das unidades de esforço de produção versus métodos de custeio tradicionais: um contraponto. Anais do Congresso Brasileiro de Custos, João Pessoa. PB, Brasil,14.

Marques, K. C. M., Camacho, R. R., \& Alcantara, C. C. V. de. (2015). Avaliação do rigor metodológico de estudos de caso em contabilidade gerencial publicados em periódicos no Brasil. Revista Contabilidade \& Finanças, USP, 26(67), 27-42.

Martins, E., \& Rocha, W. (2010). Métodos de custeio comparados: custos e margens analisadas sob diferentes perspectivas. São Paulo: Atlas.

Meyssonnier, F. (2003). L'approche des coûts complets par les équivalents de 
production, voie d'avenir ou impasse? (une analyse de la méthode GP-UVA). Comptabilité-Contrôle-Audit, 9(1), 111-124.

Oyadomari, J. C. T., Cardoso, R. L., Mendonça, O. R. Neto, Antunes, M. T. P., \& Aguiar, A. B. (2013). Criação de conhecimento em práticas de controle gerencial: análise dos estudos internacionais. Advances in Scientific and Applied Accounting, 6(1), 430 .

Pereira, S. I. M. (2015). Custeio por atividades (ABC) e unidade de esforço de produção (UEP): similaridades, diferenças e complementariedades. (Dissertação de Mestrado). PPGCC. Universidade de São Paulo - USP, São Paulo, SP, Brasil.

Raupp, F., \& Beuren, I. (2010). M. Metodologia da pesquisa aplicável às ciências sociais. In: Beuren, I. M. Como elaborar trabalhos monográficos em contabilidade (3a ed.). São Paulo: Atlas.

Salomon, D. V. (1999). Como fazer uma monografia. São Paulo: Martins.

Schultz, C. A., Silva, M. Z. da, \& Borgert, A. (2008). É o Custeio por Absorção o único método aceito pela Contabilidade? Anais do Congresso Brasileiro de Custos, Curitiba. PR, Brasil, 15.

Silva, E. L., \& Menezes, E. M. (2005). Metodologia de pesquisa e elaboração de dissertação (4a ed.). Florianópolis: LED.

Slavov, T. N. (2013). Gestão estratégica de custos: uma contribuição para a construção de sua estrutura conceitual. (Tese de doutorado). PPGCC. Faculdade de Economia, Administração e Contabilidade da Universidade de São Paulo, FEA/USP, São Paulo, Brasil.

Souza, F. R. (2014). Tempo e unidade de rede: equivalência de produção em serviços de telecomunicações. (Dissertação de Mestrado). Universidade Federal de Santa Catarina. Florianópolis, SC, Brasil.

Souza, M. A. de. (2011). Mensuração e custeio: fundamentos de custos para gestão. In: Parisi, C., \& Megliorini, E. (org.). Contabilidade gerencial. São Paulo: Atlas.

Souza, M. A. de, \& Diehl, C. A. (2009). Gestão de custos: uma abordagem integrada entre contabilidade, engenharia e administração. São Paulo: Atlas.

Walter, F., Schultz, C. A., Dantas, Y. G. C., \& Confessor, K. L. A. (2009). O perfil dos artigos sobre o Método das UEPs nos anais do Congresso Brasileiro de Custos e 
do Encontro Nacional de Engenharia de Produção. Anais do Congresso Brasileiro de Custos, Fortaleza. CE, Brasil, 16.

Walter, F., Confessor, K. L. A., Bezerra, F. G., Maciel, B. S. L., \& Amorim, B. P. (2016). Método das Unidades de Esforço de Produção: um perfil dos estudos de caso. Espacios, 37(3), 4.

Wernke, R., Junges, I., \& Cláudio, D. A. (2012). Indicadores não-financeiros do método UEP aplicáveis à gestão de pequena indústria. Iberoamerican Journal of Industrial Engineering, 4(8), 125-145.

Wernke, R., Junges, I., \& Lembeck, M. (2015). Comparativo entre os métodos UEP e TDABC: estudo de caso. Revista Ambiente Contábil, UFRN, 7(1), 51-69.

Wernke, R., Junges, I., Lembeck, M., \& Zanin, A. (2015). Determinação do custo fabril pelo método UEP: estudo de caso no setor de salsicharia de frigorífico. GEPROS. Gestão da Produção, Operações e Sistemas, 10(1), 139-156.

Wernke, R., \& Lembeck, M. (2012). Método UEP como facilitador da aplicação do CPC16-Estoques pela contabilidade de custos: estudo de caso. Anais do Congresso Brasileiro de Custos, Bento Gonçalves, RS, Brasil, 19.

Wernke, R., Lembeck, M., Junges, I., \& Ritta, C. O. (2013). Método UEP: estudo de caso sobre a aplicabilidade em pequena fábrica de confecções femininas. Iberoamerican Journal of Industrial Engineering, 5(9), 296-319.

Yin, R. K. (2005). Estudo de caso: planejamento e método. Porto Alegre: Bookman.

Zonatto, V. C. da S., Silva, M. Z. da, Toledo, J. R. de Filho, \& Drebes, A. V. (2012). Utilização do método de Unidade de Esforço de Produção (UEP) para determinação dos custos de transformação de uma indústria de vidros curvados para refrigeradores comerciais. Revista Gestão Industrial, UTFPR, 8(1), 233-248.

Data de Submissão: 21/12/2018

Data de Aceite: 28/11/2019 